\title{
Consumer usage behavior of internet-based services (IBS) in Pakistan during COVID-19 crisis from the perspective of technology acceptance model
}

\author{
Nasir Ishfaq ${ }^{1}$ Huang Mengxing ${ }^{1}$ \\ Received: 21 May 2021 / Accepted: 4 August 2021 / Published online: 22 September 2021 \\ (C) The Author(s), under exclusive licence to Springer-Verlag GmbH Germany, part of Springer Nature 2021
}

\begin{abstract}
This study aims to explore the factors that affect consumers' behavior in adaptation and use of internet-based services (IBS) during the COVID-19 crisis. In this study, technology acceptance model (TAM) was applied to predict the behavioral intention of active social media users among the Pakistan population based on the revised model of the TAM model. And the data of external factors facilitating conditions (FC), social impact (SI), and task technology fit (TTF) were collected from active social media users of Pakistan by using structured questionnaires. After performing Pearson's correlation and linear regression on the collected data, findings have shown that the outcome variable, i.e., behavioral intention, exhibited significant correlation with all variables except for perceived ease of use (PEoU). Further analysis revealed mixed results wherein FC and TTF can make a significant influence on perceived usefulness (PU) and PEoU, respectively. In addition, PU can significantly affect attitude (ATT) towards the use of IBS while the use of IBS has been affected by behavioral INT during the outbreak of COVID-19 in Pakistan.
\end{abstract}

Keywords Technology acceptance model (TAM) $\cdot$ Task technology fit $\cdot$ Social impact $\cdot$ Facilitating conditions

\section{Introduction}

With the spread of COVID-19, almost no single country and territory across the world remain unaffected. The pandemic has ultimately resulted in a complete lockdown and shutting down of activities (Paital et al. 2020; Bahadur et al. 2020). This lockdown has taken most people to the era where individuals use the internet and internet-based services (IBS) for communication and interaction, and continue their job and home-based responsibilities (Singh et al. 2021). Although these issues have been addressed, due to the pandemic, people come to a situation where using the internet has become essential for survival. Moreover, due to the rising use of IT

Responsible Editor: Lotfi Aleya

Huang Mengxing

huangmx09@163.com

1 College of Information and Communication Engineering, Hainan University, Haikou City, China platforms and increase usage of the internet, a substantial shift has been observed in usage patterns and behaviors. People who work in the field of business, society, or government have been adapting quickly to new "styles"-with interactive online meetings, shifting office-based to home tasking with new emerging technologies, and adopting behavioral and usage patterns (Sathish et al. 2020). China has observed the changes in the consumers' behavior in food purchasing and consumption during COVID-19. During COVID19 in China, gender and age were the relevant factors that affect sustainable behavior. The size of household can make a significant effect on the healthy diet shift and food waste reduction while risk attitude makes a negative and significant impact on the sustainable purchase decision (Li et al. 2021).

Against the context of the COVID-19, people have been witnessing the extensive and continuing use of the internet and such information systems at the same pace to communicate, interact, and work online from home (Kamal 2020). As an outcome of pandemic COVID-19, lockdowns have observed this surge in IBS usage in various scenarios of different nature. In the backdrop of wide use of information technology at individual and group levels, organizations have been improving their technologies and infrastructure to meet the needs 
of users which have immensely grown since there is a wide usage of smartphones, laptops, and computers. With strict social and physical distancing measures in place on account of health advisory regulations imposed by different countries in the interest of their public, the adaptation on new routines engage accessing the IT platforms, particularly the internet for most services in the field of education, health, financial institutions, press, social media, electronic/smart commerce, and many more (Dutta and Fischer 2021).

In terms of the education, there is a dramatic shifting of traditional classes to the online mode of conducting classes (Tang et al. 2020). On account of extensive lockdown, no matter of public or private schools, colleges, and universities around the world including Pakistan have used video and web conferencing platforms such as Zoom, Google Meets, and Microsoft Teams, whereas some of the institutions have shifted to both modes: on-campus and online classes (Soni 2020). Students are also using different social apps to exchange information for educational purposes. Business sustainability is one of the major concerns during COVID-19 and emergency response planning, social distances, modification of working hours, and just-in-time delivery are the most affecting factors making an impact on the corporate business sustainability (Ikram et al. 2020; Rubab et al. 2021).

For working online from home during the pandemic, organizations have been hiring workers on an informal basis like subcontract and ad hoc basis (Roy et al. 2020). Owing to the availability of internet-based services, some of the organizations in Pakistan work from home and the workplace on alternative days with an exemption of attendance (Hasan et al. 2021), while millions of people have lost their jobs due to the gig economy wherein organizations have already shut down their businesses because of the COVID-19 crisis (Coibion et al. 2020). In addition, digital technology has made the monitoring organization, calling, and locating of their workforce accessible at any time. Irrespective of increased productivity and continuance availability for work and staying with digital devices, employees of the organization do not find time to refuge from constant work pressure (Fana et al. 2020).

With the wide use of technologies in meeting basic life needs, researchers have tried to understand the usage patterns and behaviors of individuals involved in adaptation and use of technology particularly internetbased services (Pandey and Pal 2020). To foster the adaptation of internet-based technology and services among people, and to analyze the factors that affect their perception are of vital significance. Under the effect of worries for health and economic conditions, the behavior of consumer has changed during COVID-19. Consumer interest in spending has been decreased because health conditions can make an impact on the traditional and online shopping during the pandemic (Eger et al. 2021; Bhatti et al. 2019).

Due to the virus-carrying risk of banknotes and coins and the encouraging role of governments in the prevention of the COVID-19, digital payments and currencies to help people get well-being has been rising (Allam 2020). In addition, the provision of delivery services requires customers to make online payments through debit or credit cards which also results in a surge in internet technology usage (Pandey and Pal 2020).

The pandemic has advanced the rise of the internet-based services, and users consume more time in online movies and social networks. According to MIT Technology Review, there is a $25 \%$ increase in the usage of the internet during the COVID-19 with a substantial shift in users' behavior in Pakistan (Javed 2020). And a number of studies proved that IBS could make an impact on consumer activities during the pandemic. According to the report of TR Pakistan, there has been an observed $25 \%$ increase in internet usage in Pakistan during the Pandemic COVID19 crisis. Moreover, according to the statistics of the Pakistan Telecommunication Authority 2019, reports have shown that during $2019,83 \%$ of the population is active social media users in Pakistan which use social media every day (Farooq and Raju 2019). Thus, understanding the behavior towards the use of internet-based services (IBS) in a large range of population during the COVID-19 health emergency is prominent in Pakistan. This study aims to reveal and highlight the impact of COVID-19 on consumer behavior during IBS.

Using the technology acceptance model (TAM) as the main theoretical guidance, this research proposed a study model. The study model focused on the impact of already defined factors of different internet-based services from the perspective of developing countries like Pakistan which is largely hit by COVID-19 (Ali et al. 2020) and where people are showing an increasing trend towards the use of IBS as means of doing tasks from indoor to outdoor activities by using online questionnaire-based survey.

The outline of the paper is organized as follows: the "Research background" section mainly introduces a short overview of TAM and its constructs along with a research background for establishing factors that influence customer's behavior towards the use of internet-based services during the COVID-19. The hypothesis development and the research methodology are described in the subsequent "Research model and hypothesis development" and "Research methodology" sections. Results of data analysis are introduced in the "Results" section, while the discussion is in the "Discussion and policy recommendation" section. The "Conclusions" and "Limitations" sections 
introduce the conclusions, suggestions, and the limitations of the current research.

\section{Research background}

With the rapid development of the field, understanding and predicting user's behavior for adaptation and use of technology has been the focus of many researchers and scholars for decades. The researchers have been trying to explore the factors that help to determine the customer's behavior involved in deciding and making use of information technology. In addition, researchers attempt to understand the behavior of users towards the use of internet-based services due to the wide acceptance of this technology by using different theories and approaches.

\section{Technology acceptance model}

Among various theories and approaches, the TAM model has been extensively used in information technology and internetbased services to understand the adaptation decision-making process.

This model suggests that an individual's perception to believe in and use of new technology is based on two determinant variables: perceived usefulness (PU) and perceived ease of use (PEoU). According to Davis (1989), these two variables' constructs are logically the rationale points behind the decision whether to adopt a new technology or not. Using internet-based services by individuals is one of the implications in the field of information technology.

The present prevailing situation of COVID-19 across the world particularly in Pakistan has necessitated the study of this model in technology adaptation as a trend has been seen in a $25 \%$ increase in internet usage during the COVID-19 according to a figure reported on 16 September 2020 by TR Pakistan. This model helps us to understand the behavior of internet users behind this increasing trend of internet usage as a necessity during the COVID-19 as the behavioral and usage patterns of many individuals have changed in this health crisis (Ait Youssef et al. 2020; Shuaib et al. 2020).

Behavior can be defined and determined by many factors that affect behavior intention and subsequently adopt behavior including the use of IBS. This will depend on individuals' willingness to act with how much effort to use in performing that behavior (Beck and Ajzen 1991). With the use of IBS, behavior intention in turn can be determined by a direct effect of individual's attitude and direct/ indirect effect of PU and PEoU and other external factors which leads to the actual behavior. External factors may affect behavioral intention via direct, indirect, and mediating pathways.

Many studies have explored TAM model with external factors (Ait Youssef et al. 2020; Al-Okaily et al. 2020; BrizPonce et al. 2017; Chen et al. 2011; Cordente-Rodriguez et al. 2020; Hur et al. 2015; Nikou et al. 2017; Okcu et al. 2019; Rafique et al. 2019; Sagnier et al. 2020; Saleem et al. 2020; Singh and Srivastava 2019; Sukendro et al. 2020; Teo et al. 2019; Wismantoro et al. 2020; Watat et al. 2020; Wu and Chen 2017; You et al. 2020), and without integrated external variables (Davis 1989; Kong et al. 2020), in TAM model regarding behavioral intention and use of different technological implications.

Individual attitude plays an important role in determining behavioral intention to use and adapt the particular behavior. This study studied the attitude towards behavior involved in IT and its implications during the outbreak of COVID-19. Empirically validated studies (Kong et al. 2020; Wu and Chen 2017) are available in which the relationship of attitude and behavioral intention has been proved.

Therefore, perceived usefulness can be expressed as the degree of individual user's belief that using internet-based services during COVID-19 would bring improved performances (Davis 1989, Okcu et al. 2019), in the context of communication, interaction, and work. Several researchers' findings have supported the significant contribution of perceived usefulness towards individuals' attitude (BrizPonce et al. 2017; Teo et al. 2019; Wu and Chen 2017), and behavioral intention (Ait Youssef et al. 2020; AlOkaily et al. 2020; Cordente-Rodriguez et al. 2020; Kong et al. 2020; Nikou et al. 2017; Okcu et al. 2019; Rafique et al. 2019; Saleem and Nor 2020; Teo et al. 2019; $\mathrm{Wu}$ and Chen 2017; You et al. 2020), to use information technology in various contexts.

This study supposes perceived ease of use as the degree of individual's effort that using internet-based services during COVID-19 would believe to be easy and free of efforts (Davis 1989). If individuals perceive the task is easy to perform, people are more likely to be involved in performing that task and show a positive predisposition towards that task (David 1989). A large number of studies have proved that the effects of perceived ease of use on attitude (Briz-Ponce et al. 2017; Kong et al. 2020; Sukendro et al. 2020; Teo et al. 2019), and behavioral intention (Ait Youssef et al. 2020; Al-Okaily et al. 2020; Kong et al. 2020; Nikou et al. 2017; Okcu et al. 2019; Rafique et al. 2019).

Irrespective of empirically proved relationships among PU, PEoU, and attitude, a behavioral intention that is not deemed sufficient (Ait Youssef et al. 2020), there is a need to consider external variables which may or may not affect users' perception regarding the use of internet-based services. However, 
sometimes this model alone does not provide sufficient explanation regarding the user's perception of adaptability and usage of new technology. Therefore, it is imperative for researchers to integrate external factors into the TAM model affecting the user's perception regarding adaptation and use of internet-based services. The external variables elected in this study are based on results of current studies wherein relationship/impact of external variables has been empirically proved irrespective of empirically proved relationships among perceived usefulness, perceived ease of use, attitude, and a behavioral intention which does not suffice (Ait Youssef et al. 2020); there is a need to consider external variables which may or may not affect users' perception regarding the use of internet-based services. External variables chosen in this study are based on results of current studies wherein the relationship/impact of external variables has been empirically proved (Ait Youssef et al. 2020; Al-Okaily et al. 2020; Briz-Ponce et al. 2017; Cordente-Rodriguez et al. 2020; Nikou et al. 2017; Sukendro et al. 2020; Teo et al. 2019; Wismantoro et al. 2020; Wu and Chen 2017; You et al. 2020), irrespective of the fact whether these studies were conducted pre- and post-COVID-19 situations.

\section{Facilitating condition}

Against the context of using IBS by individuals, facilitating condition (FC) can be described as the degree of individuals who believe in the existence of organizational and technical infrastructure to aid in support of IBS usage. Numerous studies have empirically supported the relationship of facilitating conditions with perceived usefulness (PU) and perceived ease of use (PEoU) (Nikou et al. 2017; Sukendro et al. 2020; Teo et al. 2019).

\section{Social impact}

Social impact (SI) can be described as "social pressure being perceived to decide whether to perform the behavior or not" (Ajzen. 1991). Individuals adapt particular behavior because of their perceptions and views of others. In support of the significance of social impact on perceived usefulness (Nikou, et al. 2017, Wu and Chen 2017), attitude (BrizPonce et al. 2017; Wu and Chen 2017), and behavioral intention (Ait Youssef et al. 2020; Al-Okaily et al. 2020; Briz-Ponce et al. 2017; Cordente-Rodriguez et al. 2020) regarding use of information technology, studies were conducted.

\section{Task technology fit}

The term "task technology fit" is defined as "the degree of matching the capabilities of IT with the tasks of users," which explains the job performance levels of individuals towards a particular job. A large number of studies have validated the effect of task technology fit on the perceived usefulness (Wu and Chen 2017; You et al. 2020), perceived ease of use (Wu and Chen 2017), attitude, and behavioral intention to use an implication of particular IT.

A large number of studies have empirically been validated to understand the individual's behavior and relationship of various constructs during this health crisis of the COVID-19.

Saleem and Nor (2020) assessed the factors of consumer's intention for adaptation of e-commerce during COVID-19 disease in Saudi Arabia. Snowball sampling technique was employed for taking sample of social media users, and an online questionnaire was used for data collection from the sample. Statistical techniques were used to assess the impact of independent variables among which PU, risk-taking propensity, perceived behavioral control (PBC), perceived lack of alternatives, and government support were found to have a significant impact on Saudi consumer's intention during the COVID-19 outbreak for technology adaptation.

Aid Youssef et al. (2020) investigated the factors involved in affecting consumer's attention to use online mode of purchasing during the outbreak of COVID-19 in Morocco. For this purpose, the impact of TAM constructs, social impact, and structural assurance was studied to understand the consumer's behavioral intention for online shopping. Data was collected through online questionnaire distribution from internet/online shopping service users. Based on the findings of statistical techniques used in a study, all variables under study were significantly related to usage intention during a health crisis and PU, PEoU, social impact, and structural assurance have a significant influence on usage intention during the COVID-19 problems in Morocco.

Al-Kaila et al. (2020) explored the determinant factors of student's intention to use e-learning systems during prevailing COVID-19 circumstances of Jordan. For data collection, a survey-based questionnaire was used. In this study, it was revealed from findings that all study variables PEoU, PU, and subjective norms have significantly and positively affected the student's intention of using e-learning systems, and mediating effects of PEoU and PU are also confirmed between subjective norms and student's intention. Additionally, the significant impact of subjective norm among PEoU and PU of e-learning acceptance among students during the COVID-19 circumstances in this study is also proved.

Sukendro et al. (2020) used extended technology acceptance model to predict the use of Indonesian students' e-learning system based on TAM constructs and 
Table 1 List of proposed hypotheses

\begin{tabular}{lll}
\hline Factors & Abbrev & Hypotheses \\
\hline $\begin{array}{l}\text { Facilitating } \\
\text { conditions }\end{array}$ & (FC) & H1: FC influences PU to use internet-based services during COVID-19. \\
Social impact & & H2: FC influences PEoU to use internet-based services during COVID-19. \\
& (SI) & H3: SI influences PU to use internet-based services during COVID-19. \\
Task technology fit & (TTF) & H5: TT influences PEoU to use internet-based services during COVID-19. \\
& & H6: TTF influences PEU to use internet-based services during COVID-19. \\
Perceived usefulness & (PU) & H7: PU influences AT to use internet-based services during COVID-19. \\
Perceived ease of use & (PEoU) & H8: PEoU influences AT to use internet-based services during COVID-19. \\
Attitude & ATT & H9: AT influences INT to use internet-based services during COVID-19. \\
\hline
\end{tabular}

facilitating condition used as an external factor. During the outbreak of COVID-19, an online survey applicationbased study with partial least square structural equation modeling was conducted for data collection and analysis from students of Indonesian higher education institutions. Findings of the study have revealed the significant impact of facilitating conditions on PEoU and PU, whereas attitude has significantly affected the use of elearning systems via direct and indirect paths. An insignificant impact of PU on attitude was also reported in this study.

\section{Research model and hypothesis development}

Using the understanding of current research studies and the findings on the TAM model and other external variables, a conceptual model identifying several attributes as predictors of usage intention towards using internet-based services, is proposed (Table 1).

The relationship between these attributes integrated with this theoretical framework is shown in Fig. 1.

\section{Research methodology}

The research aims to ascertain the impact of underlying factors of the TAM model and other external factors involved in the behavioral intention to use the internet-based services (IBS) during the COVID-19 country-wide situation of Pakistan. To meet the research objective, the data to be collected is of vital importance and a survey-based methodology is applied. Figure 1 shows the research model of this study where "intention to use internet-based services" is considered a dependent variable and is determined directly by "attitude (AT) to use" and indirectly by perceived usefulness (PU), perceived ease of use (PEoU), and other external variables, namely facilitating conditions (FC), social impact (SI), and task technology fit (TTF).

The target population for this research is IBS users of Pakistan who are among $83 \%$ of active social media users and are involved in using different social media apps and websites (particularly highlighted in PTA 2019 Report). The recruitment of respondents to participate in this study has certain criteria. Firstly, they have easy internet access and use internet-based services through smartphone technology and computer-based technology. Secondly, they use the internet every day. All respondents were informed about the purpose of this study and consent of every respondent was ensured before distributing the link of questionnaire online through Google Forms in different groups. To ensure the validity of the study, the individual determinant constructs to be studied are adopted from previous studies, the details of which are provided in Appendix 1.

\section{Research instrument and data collection}

An instrument used for data collection from IBS users comprises closed-ended and structured questionnaires. The questionnaire is randomly distributed online to different social media platforms including mobile applications due to government health advisory guidelines on social/physical distancing issued from time to time. The questionnaire comprises two sections: the first section on demographic responses followed by the second section which mainly consists of questions being asked to know about the individual responses for item construct understudy in the above lying research model (Fig. 1). Section A contains demographic information such as gender, age, education, use of the internet (yes or no), and frequency of access to the internet (everyday use) based on the PTA 2019 report who are $83 \%$ of total internet media users. This study employed a 5-point Likert scale and the scale oscillated between responses 


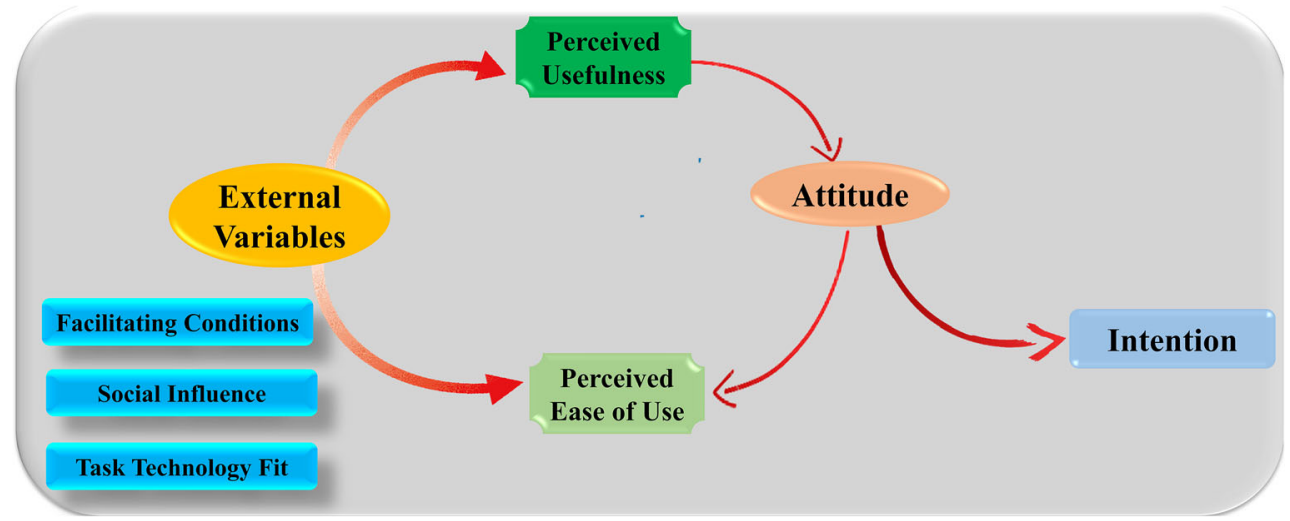

Fig. 1 Framework of relationship between attributes used in this study

greatly disagree (1) to greatly agree (5). To validate the questionnaire, a pilot study was conducted by consulting a questionnaire with field specialists and research scholars. The participant was chosen because of their technical field competences and thorough understanding of IBS. Questionnaires collected from the pilot study assisted in improving its effectiveness with some specific adjustments in terms of its content and quality. Figure 2 shows the research methodology steps:

The data was collected from 206 respondents; out of which, 12 responses had been excluded from the study based on the criteria that they are non-internet users. Therefore, the response rate of the target sample accounts for $94 \%$.

\section{Data analysis}

The data which were collected from the respondents were analyzed by using SPSS 23 to check the reliability of the construct items and correlation followed by using regression to quantify the impact of independent variables of the study on the dependent variables Appendix 2.

\section{Results}

Three types of analysis were utilized to validate the methodology. Firstly, reliability analysis was conducted to validate the questionnaire. This indicator is the internal consistency of the questions used in the questionnaire, which is a test of internal correlation. The higher the correlation, the better the reliability. Next, external correlation between the factors was built to test the results of variables relating with each other in proposed hypothesis. In the end, the regression analysis was applied to check the relations among variables.

\section{Reliability test}

To measure the reliability of variables, Cronbach's alpha was calculated by using SPSS package software. Results of the test showed that the overall reliability of all variables was found to be 0.704 , whereas individuals' Cronbach's alpha values for all variables are given in Table 2.

\section{Spearman's correlation matrix}

Pearson's correlation matrix was measured by using univariate analysis in SPSS. The results of the correlation matrix are reflected in Table 3.

Results of Pearson's correlation matrix show that all variables except for the perceived ease of use (PEoU) are found to have a significant relationship with behavioral intention (dependent variable). Perceived usefulness and social identity has also insignificant relationships with variable attitudes. There also exists an insignificant relationship between social identity and perceived ease of use. In addition to these insignificant relationships, significant correlations existed among other constructs.

\section{Evaluation of research model}

Using the enter method, multiple linear regression was undertaken on different variables to explore the nature and direction and quantify of the impact of independent variables on the dependent variables. And six predictors were loaded into the 
model that explains sample outcome variance by $27.8 \%$ (Adj $R^{2}=.278$ ) and significantly predicts the outcome variable of behavioral intention. Results of regression analysis performed on the variables are depicted in Tables 4 and 5 .

Dependent variable is behavioral intention (INT)

Applying 1\% level of significance, findings of regression analysis have shown that out of 9, 4 hypotheses are supported except for $\mathrm{H} 1 . \mathrm{H} 3, \mathrm{H} 4, \mathrm{H} 6$, and $\mathrm{H} 7$ in which it is reflected that among external variables, social identity (SI) $(\beta=.108, t=$ $1.375, p<.001)$ and $\mathrm{FC}(\beta=.135, t=1.956, p<.001)$ are found to exert insignificant effect on perceived usefulness $(\mathrm{PU})$; hence, $\mathrm{H} 1$ and $\mathrm{H} 3$ are rejected, whereas SI $(\beta=-$ $.158, t=-1.920, p<.001)$ and task technology fit (TTF) $(\beta$ $=.242, t=2.876, p<.001)$ have insignificant influence on perceived ease of use (PEoU); thus, $\mathrm{H} 3$ and $\mathrm{H} 6$ are rejected.

Among determinants of attitude in the TAM model, only PU has insignificant impact on attitude $(\beta=-.168, t=-$ $2.501, p<.001)$, whereas PEoU significantly contributed towards individuals' attitude (ATT) $(\beta=.580, t=8.634, p<$ $.001)$. Therefore, $\mathrm{H7}$ is rejected; in contrast, $\mathrm{H} 8$ is supported.

Four of the independent variables are found to exert significantly impact on the dependent variable. TTF significantly contributed to $\mathrm{PU}(\beta=.327, t=4.069, p<.001)$. FC was significantly related to PEoU $(\beta=.288, t=4.006, p<.001)$ which in turn significantly affected the ATT $(\beta=.580, t=$ $8.634, p<.001$ ) of IBS users towards use of services. ATT subsequently has also significant contribution towards behavioral intention of individuals $(\beta=.264, t=3.800, p<.001)$. Therefore, H2, H5, H8, and H9 are supported.

\section{Discussion and policy recommendation}

In several studies, the TAM model was used to predict the behavioral adaptation and acceptance regarding the use and implications of information technology. Perceived usefulness and perceived ease of use are the variables on which the TAM model has relied. Recent studies aimed at external factors, i.e., FC, SI, and TTF being used to affect the individual behavior has not accounted for effects of the same variables regarding the use of internet-based services (IBS) during COVID-19 in Pakistan. Therefore, this study has been concluded with the integration of these external factors into the traditional model of TAM developed by David et al. (1989).

Zhu and Zhang (2010) believes that the characteristics of online consumers are roughly divided into several categories: first, there are obvious differences in consumer demand; second, online consumption is hierarchical; third, consumption has network externalities; fourth, impulsive consumption has increased. Chaudhary (2020) and Bhatti et al. (2020) analyzed the characteristics of consumer behavior in the e-commerce environment relative to the performance of traditional business models: first, the segmentation of the consumer market; second, the mainstreaming of service demand; third, the expansion of the range of choices and the rationalization of purchase behavior; fourth, the directization of production and circulation cycles. Finally, a consumer behavior model based on the theory of planned behavior under the e-commerce environment is established.

Against the context of IBS, research findings are in the support of the TAM model to a lesser extent to understand the behavior of individuals. The above findings show that FC are shown to have a significant impact on perceived ease of use (PEoU). However, it can be inferred that the availability of guidance, resources, and technical assistance might enhance the beneficial impacts of using IBS during this health crisis perceived by Pakistanis. The finding corresponds with the findings of previous studies (Nikou and Economides 2017; Sukendro et al. 2020). Whereas TTF is shown to exhibit a significant contribution to perceived usefulness (PU) which is supported by studies (Wu and Chen 2017; You et al. 2020). Individuals think about the usability of IBS apps or services only when these services are deemed appropriate to match with their needs and abilities to use these services. $\mathrm{PEoU}$ is also reported to have significance in terms of relationships and impact on the individuals' attitude towards using IBS during the outbreak of COVID-19 which also agrees with the findings of studies conducted by Briz-Ponce et al. (2017), Kong et al. (2020), Sukendro et al. (2020), and Teo et al. (2019). Results can be used to infer whether users think that using IBS is user-friendly and effortless; most likely, they are to show a positive attitude towards using such IBS in their daily activities. The significant impact of ATT on behavioral intention (INT) is supported by previously conducted studies (Briz-Ponce et al. 2017; Kong et al. 2020; Sukendro et al. 2020; Wu and Chen 2017). Based on such findings, it can be argued that the more positive individuals have in their attitude towards using IBS, the more likely they are to show behavior towards such services. Contrary to findings of various studies, perceived usefulness has been found to have an insignificant relationship with and impact on the attitude towards the use of IBS which is supported by some of the studies (Sukendro et al. 2020). Insignificant shreds of evidence of SI on PU are supported by some of the previously conducted studies (Teo et al. 2019; Wismantoro et al. 2020). This might be the result of the perception that individuals no longer perceive IBS services as a new experience. According to some researchers, SI reflects the individuals' perception towards new technology and every individual might be familiar with these IBS tools.

To improve the usefulness of facilitating conditions regarding the use of IBS platforms, developers should provide prompt and timely support to their users at interactive platforms. In facing difficulty in solving queries and complaints, users need support from apps and websites in pursuit of their tasks. For example, if a customer wants to return the product, 


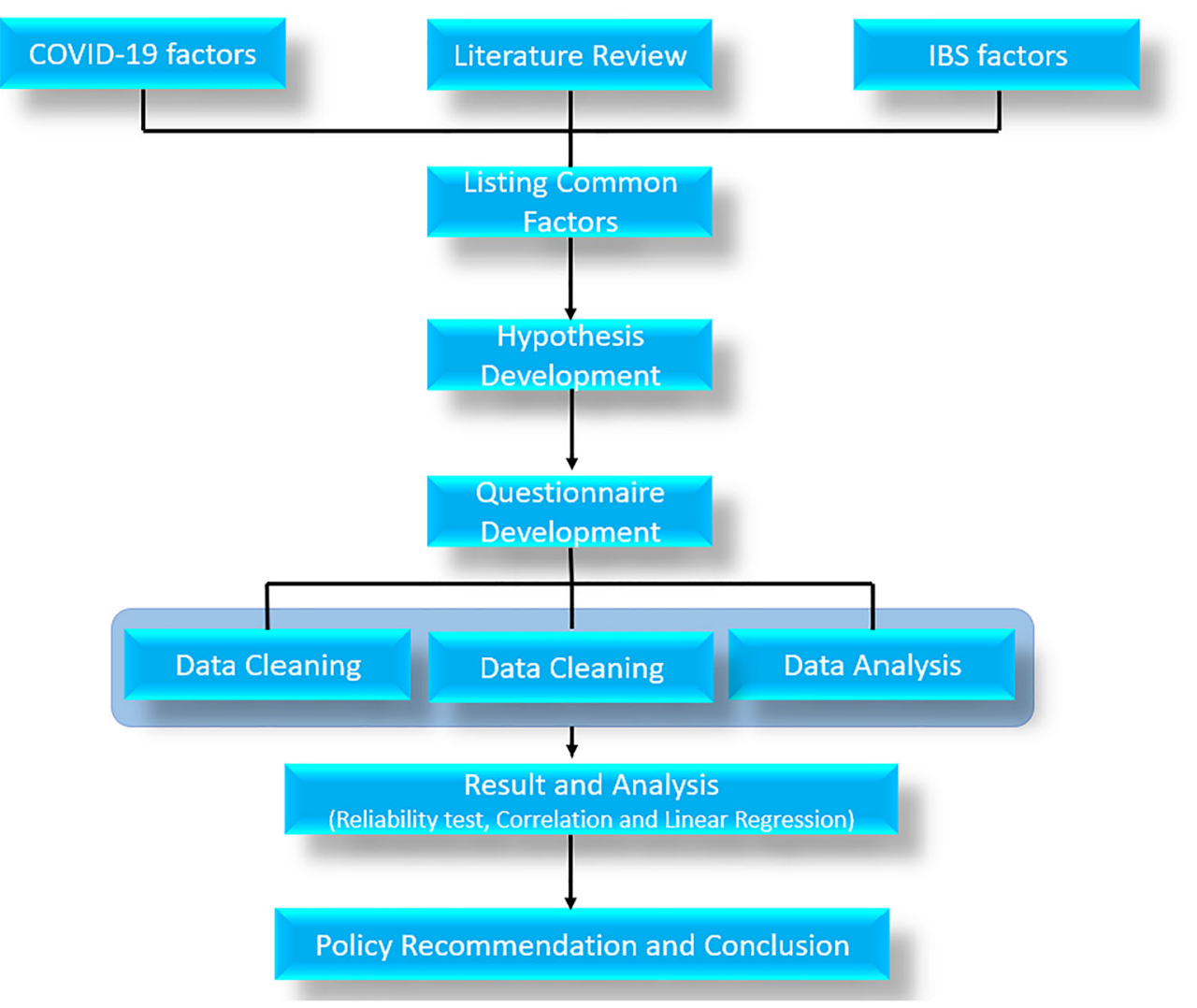

Fig 2 Research methodology steps

he/she needs proper guidelines and procedures for the return of that product. Users need a prompt response and interactive places where their queries and complaints can be heard.

For social impact on perceived usefulness and perceived ease of use, individuals who use different online services rely on the confidentiality of information and reliability of services. In the culture of Pakistan, one's behavior can be changed and affected by others' opinions. In the culture of Pakistan, opinions and views of the society have more influence on individuals' behavior. Thus, these service developers should attempt to promote the marketing of the IBS services based on regional culture. For example, present marketing of online game PUBG involves advertisement consisting of local actors to promote the usefulness and user-friendly aspects of the game. Vaccination is better solution for treatment of the disease (Bhatti et al. 2019), and it is expected that results of IBS will change once a post-COVID-19 analysis is implemented in future.

Table 2 Reliability (Cronbach's alpha coefficients)

\begin{tabular}{llllllll}
\hline FC & SI & TTF & PU & PEoU & ATT & INT & Overall \\
\hline .684 & .667 & .618 & .660 & .680 & .696 & .689 & .704 \\
\hline
\end{tabular}

\section{Managerial implications}

This study provides the supporting evidence of the significant role of facilitating conditions (FC) and task technology fit (TTF) constructs in improving the perception of users regarding ease of use and usefulness of IBS, respectively; therefore, IBS developers should work on adequate environmental and security solutions which could improve user's inconvenient experience of using IBS and befitting manner so that they can take perceived benefits from these services. IBS developers should also provide timely guidance and technical assistance in a clear and understandable manner for the safety and security of user's data and a suitable platform where they get help instantly without delay.

\section{Business implications}

$\mathrm{n}$ the process of online consumption, the behaviors of different consumer groups vary significantly. Among them, men make quicker decisions and generally do not consider the opinions of others when buying, while women will refer to others' opinions more when buying; online behaviors in economically developed areas and educationally developed areas are more common, and consumers approval is higher. Online shopping behaviors in underdeveloped areas such as rural areas are less. 
Table 3 Pearson correlation matrix

\begin{tabular}{|c|c|c|c|c|c|c|c|}
\hline & & $\mathrm{FC}$ & SI & TTF & $\mathrm{PU}$ & PEOU & ATT \\
\hline \multirow[t]{2}{*}{$\mathrm{FC}$} & Pearson Correlation & & & & & & \\
\hline & Sig. (2-tailed) & & & & & & \\
\hline \multirow[t]{2}{*}{ SI } & Pearson Correlation & $.266^{* *}$ & & & & & \\
\hline & Sig. (2-tailed) & .000 & & & & & \\
\hline \multirow[t]{2}{*}{ TTF } & Pearson Correlation & $.324^{* *}$ & $.558^{* *}$ & & & & \\
\hline & Sig. (2-tailed) & .000 & .000 & & & & \\
\hline \multirow[t]{2}{*}{ PU } & Pearson Correlation & $.271^{* *}$ & $.332^{* *}$ & $.434^{* *}$ & & & \\
\hline & Sig. (2-tailed) & .000 & .000 & .000 & & & \\
\hline \multirow[t]{2}{*}{ PEOU } & Pearson Correlation & $.324^{* *}$ & .050 & $.248^{* *}$ & $.403^{* *}$ & & \\
\hline & Sig. (2-tailed) & .000 & .493 & .001 & .000 & & \\
\hline \multirow[t]{2}{*}{ ATT } & Pearson Correlation & $.202^{* *}$ & -.043 & $.182^{*}$ & .063 & $.512^{* *}$ & \\
\hline & Sig. (2-tailed) & .005 & .550 & .011 & .387 & .000 & \\
\hline \multirow[t]{2}{*}{ INT } & Pearson Correlation & $.146^{*}$ & $.375^{* *}$ & $.462^{* *}$ & $.280^{* *}$ & .045 & $.264^{* *}$ \\
\hline & Sig. (2-tailed) & .043 & .000 & .000 & .000 & .534 & .000 \\
\hline
\end{tabular}

\section{Suggestions for internet marketing}

In view of the various problems in current online consumption during COVID-19, manufacturers need to consider the comprehensive factors that affect consumers' decision-making

Table 4 Regression analysis coefficients

\begin{tabular}{llll}
\hline & Unstandardized coefficients $(\beta)$ & $T$ & Sig. \\
\hline (Constant) & 1.936 & 7.237 & .000 \\
FC & .097 & 1.956 & .052 \\
SI & .108 & 1.375 & .171 \\
TTF & .292 & 4.069 & .000 \\
PU & -.171 & -2.501 & .013 \\
PEoU & .658 & 8.634 & .000 \\
ATT & .441 & 3.800 & .000 \\
\hline
\end{tabular}

when marketing, and solve the obstacles caused by consumers in the purchase process from all angles, so as to stimulate consumers as much as possible.

Table 5 Proposed model evaluation

\begin{tabular}{lllll}
\hline Hypotheses & Standard error & $T$ statistic & $p$-value & Results \\
\hline $\mathrm{H} 1: \mathrm{FC} \rightarrow$ PU & .049 & 7.237 & .052 & Not supported \\
$\mathrm{H} 2: \mathrm{FC} \rightarrow$ PEOU & .046 & 4.006 & .000 & Supported \\
$\mathrm{H} 3: \mathrm{SI} \rightarrow \mathrm{PU}$ & .079 & 1.956 & .171 & Not supported \\
$\mathrm{H} 4: \mathrm{SI} \rightarrow$ PEoU & .074 & -1.920 & .056 & Not supported \\
$\mathrm{H} 5: \mathrm{TTF} \rightarrow$ PU & .072 & 4.069 & .000 & Supported \\
$\mathrm{H} 6: \mathrm{TTF} \rightarrow$ PEoU & .067 & 2.876 & .004 & Not supported \\
$\mathrm{H} 7: \mathrm{PU} \rightarrow$ ATT & .069 & -2.051 & .013 & Not supported \\
$\mathrm{H} 8: \mathrm{PEoU} \rightarrow$ ATT & .076 & 8.634 & .000 & Supported \\
$\mathrm{H} 9: \mathrm{ATT} \rightarrow$ INT & .116 & 3.800 & .000 & Supported \\
\hline
\end{tabular}


1. In the sales process, there is no need to pursue "big and complete" excessively. Currently, to grasp the needs and preferences of online consumers is practical and can help achieve precise marketing, improve product targeting, and grasp customer focus.

2. Increase the construction and improvement of the logistics system. Online shopping is inseparable from the logistics distribution system. As an important part of the shopping process, logistics is an important part of the shopping process. The speed and cost of its distribution have a great impact on consumer shopping. Some manufacturers choose to hand over logistics to professional logistics companies to complete; on the one hand, it will bring consumers a better shopping experience; on the other hand, it can reduce internal complex management.

3. Strengthen the security of online payment. The payment link for consumer purchases is the link with the highest requirements for information security. A link problem of payment can lead to a loss of consumer trust and the failure transactions. Therefore, manufacturers must strengthen the payment process of online transactions.

4. Adopt a reasonable promotion method. When carrying out advertising promotion, manufacturers should choose the promotion method reasonably, consider the consumption habits of the target population, and carry out accurate advertising.

\section{Conclusions}

In addition to traditional constructs of the TAM model, additional three factors for individuals' perception involved in the use of internet-based services (IBS) are empirically tested and evaluated. The result findings reveal that PEoU, FC, TTF, and ATT significantly affect the behavioral intention of IBS users during the COVID-19 crisis in the country. So far, prior studies have not accounted for the FC, SI, and TTF as external factors in the traditional TAM model in the context of developing countries.

Although reports available online and data collected show increased internet usage for IBS on different platforms, report findings have revealed mixed results on individuals' attitude and behavioral intention of the IBS users in Pakistan. The possible explanation behind these findings is insufficient data collected for this study and the low value of $R$-square. In addition, people most probably like to indulge themselves in various outdoor activities because of the continuance of stay at home. However, due to the insufficient explanatory ability of this study, findings can provide the expected idea of taking account into other factors to understand individuals' behavior. In the future, analysis should be focused on changes of consumer behavior on IBS before and after the COVID-19.

\section{Limitations}

Firstly, the current study attempts to understand individuals' behavior by analyzing three factors external to the TAM model drawn from previous studies affecting users' attitudes and intentions towards the use of IBS during the outbreak of COVID-19 in Pakistan. In contrast to this, various other factors in real life are affecting individuals' perceptions towards the use of IBS. Secondly, the findings of this study are based on the data collected from the educated population and the people who are frequent users who are using different IT platforms every day. Due to wide use of the internet and individuals' behavioral changes, the uneducated and occasional users can be part of future studies. Thirdly, the operationalization of construct item might be a concern to be addressed in future research. Finally, due to lockdown and limited access to people, online survey questionnaires were used. However, researchers may use other means to collect the data from the target population for future studies. 


\section{Appendix 1. (Questionnaire): Consumer usage behavior of internet-based services (IBS) in Pakistan during COVID-19 crisis: a perspective of technology acceptance model}

Dear Respondents,

This study aims to predict the impact of determinant factors that affect the perception of Internet-based service users of developing countries like Pakistan during the pandemic COVID-19 and understand the behavior and perception regarding the adaptability and use of internet-based services in the field of Education, Health, Social Media Apps \& Sites, Digital Payments and Banking Services, E-Commerce, Mobile Commerce and Working from home. (As per PTA 2019 report, most visited websites are YouTube, Google, Facebook, Yahoo, WhatsApp, Wikipedia, Daraz, Twitter, Live and others are Zoom, Google Meet, Microsoft teams, video streaming, and Game Apps, etc.)

\section{(1) Strongly Disagree \\ (2) Disagree \\ (3) Neither disagrees nor agrees \\ (4) Agree \\ (5) Strongly agree}

Please tick one of the following:

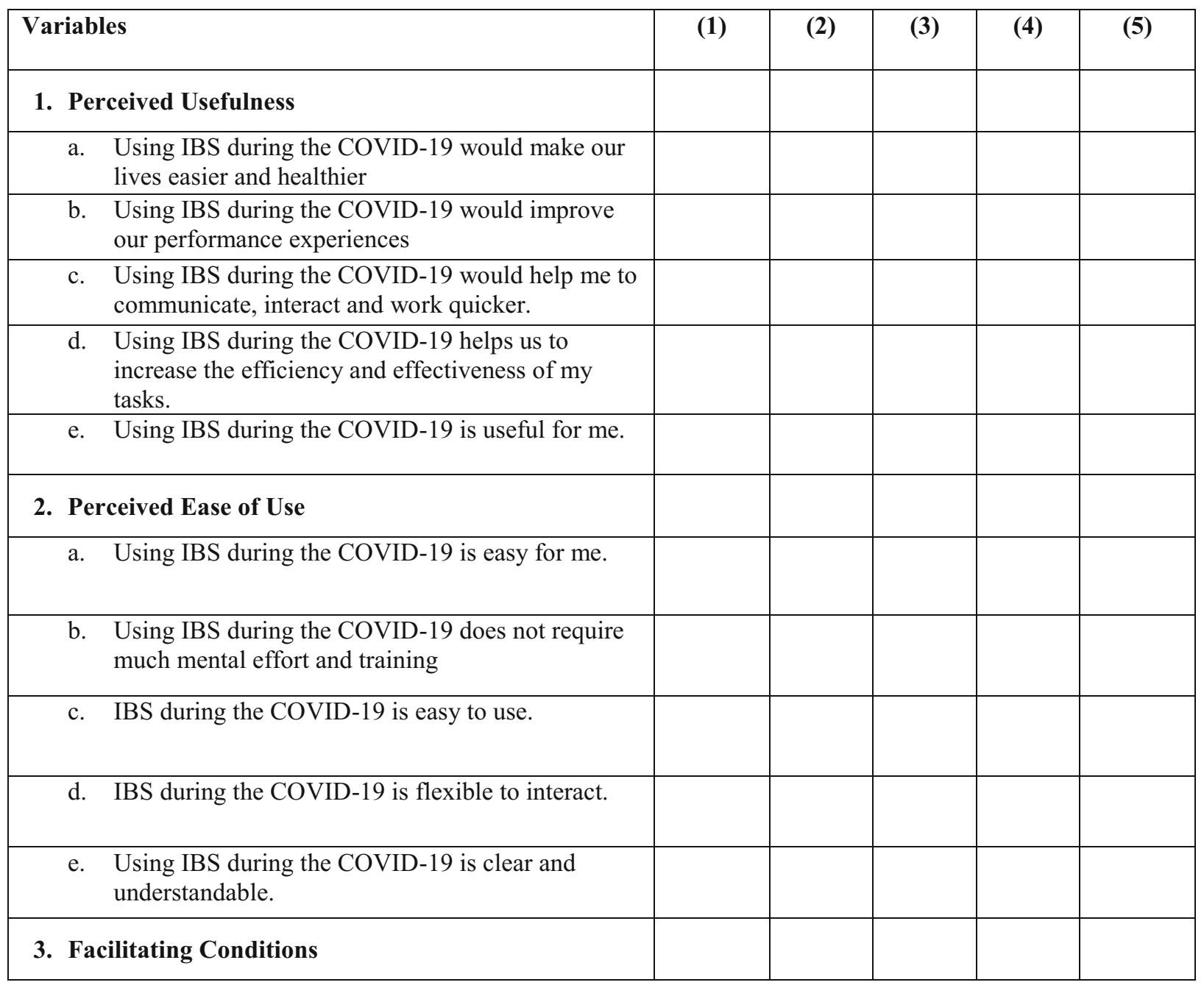




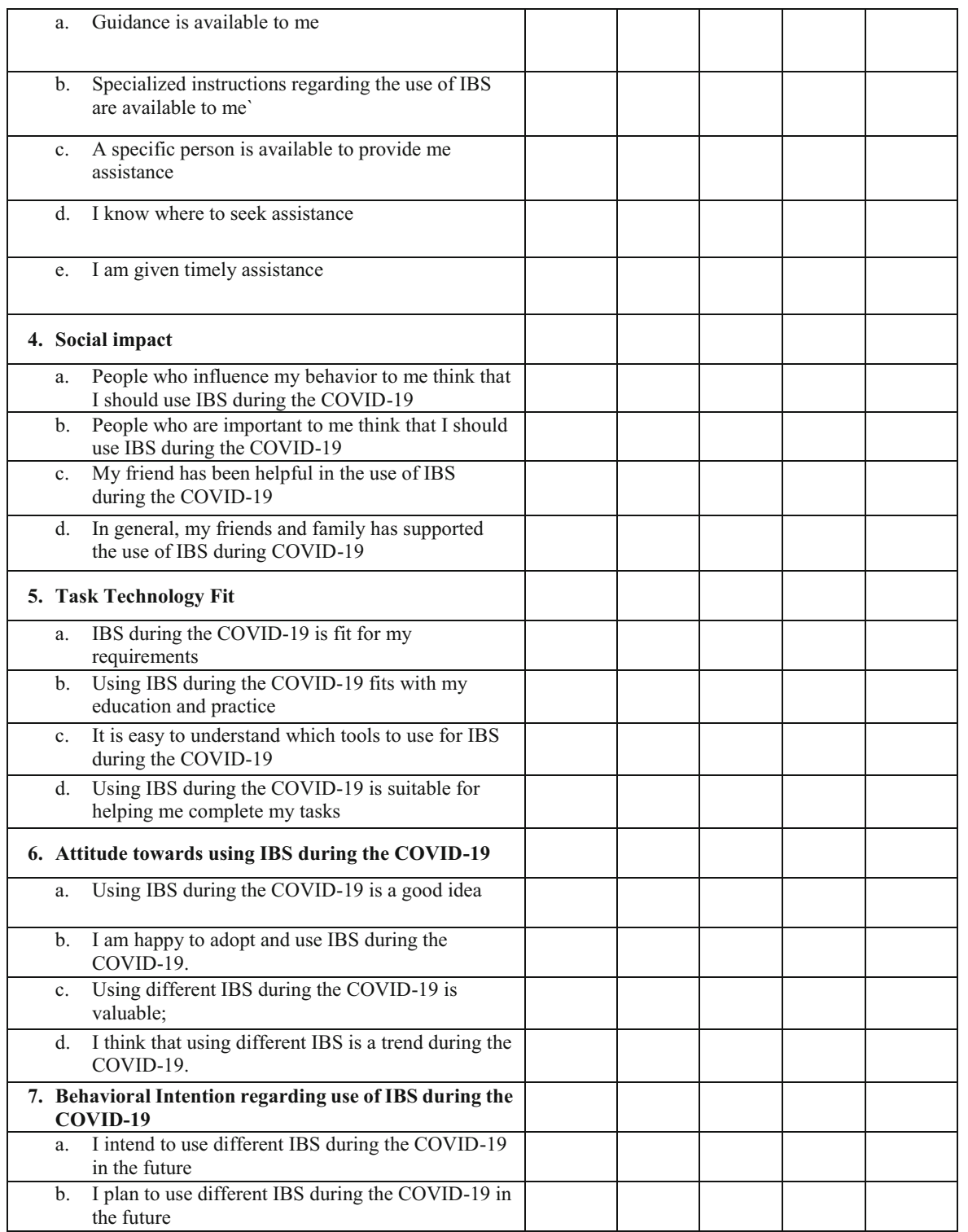

\section{Demographic Factors:}

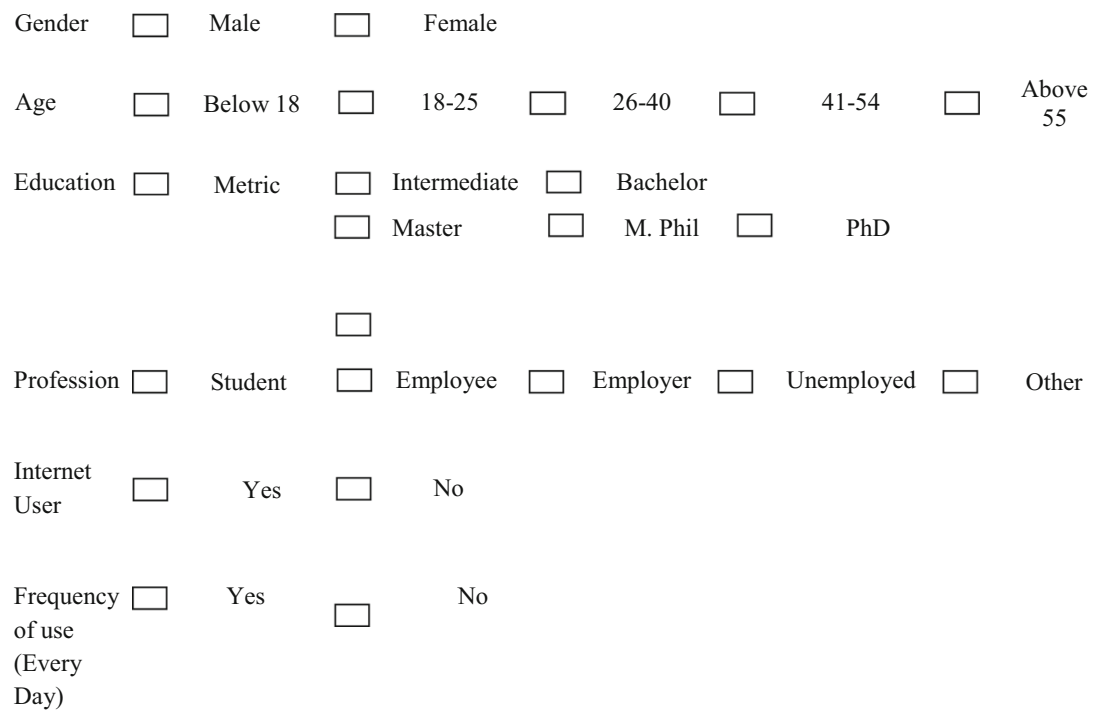




\title{
Appendix 2. Constructs, code names, and their items
}

\author{
Appendix - B Constructs, code names, and their items
}

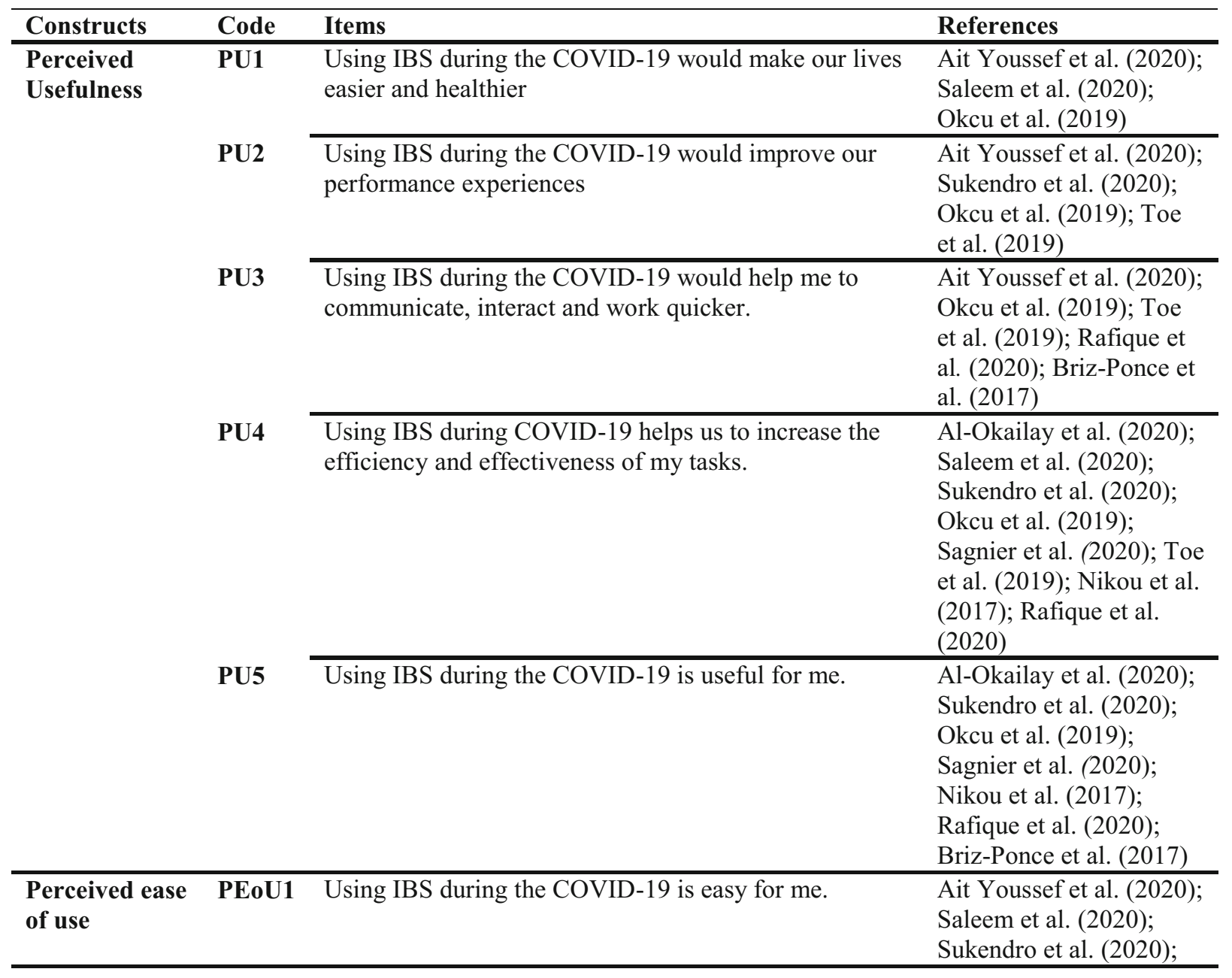


Okcu et al. (2019);

Toe et al. (2019);

Rafique et al. (2020);

Wu \& Chen (2016);

Briz-Ponce, et al. (2017);

Okcu et al. (2019)

\begin{tabular}{lll}
\hline PEoU2 & $\begin{array}{l}\text { Using IBS during the COVID-19 does not require } \\
\text { much mental effort and training }\end{array}$ & Al-Okailay et al. (2020) \\
\hline
\end{tabular}

PEoU3 IBS during the COVID-19 is easy to use. Al-Okailay et al. (2020);

Saleem et al. (2020);

Okcu et al. (2019); Toe, et al. (2019); Nikou et al. (2017); Rafique et al.

(2020); Briz-Ponce et al. (2017)

PEoU4 IBS during the COVID-19 is flexible to interact. Saleem et al. (2020); Sukendro et al. (2020); Okcu et al. (2019); Toe et al. (2019); Rafique et al. (2020)

PEoU5 Using IBS during the COVID-19 is clear and Sagnier et al. (2020); understandable.

Nikou et al. (2017);

Rafique et al. (2020) Wu

\& Chen (2016);

Briz-Ponce et al. (2017)

\begin{tabular}{|c|c|c|c|}
\hline \multirow{4}{*}{$\begin{array}{l}\text { Attitude } \\
\text { towards using } \\
\text { the } \\
\text { Internet-based } \\
\text { services } \\
\text { during the } \\
\text { COVID-19 }\end{array}$} & AT1 & Using IBS during the COVID-19 is a good idea & $\begin{array}{l}\text { Sukendro et al. (2020); } \\
\text { Toe et al. (2019); Wu \& } \\
\text { Chen (2016); Briz-Ponce } \\
\text { et al. (2017) }\end{array}$ \\
\hline & AT2 & $\begin{array}{l}\text { I am happy to adopt and use IBS during the } \\
\text { COVID-19. }\end{array}$ & \\
\hline & AT3 & Using different IBS during the COVID-19 is valuable; & \\
\hline & AT4 & $\begin{array}{l}\text { I think that using different IBS is a trend during the } \\
\text { COVID-19. }\end{array}$ & Sukendro et al. (2020) \\
\hline \multirow[t]{2}{*}{$\begin{array}{l}\text { Behavioral } \\
\text { Intention } \\
\text { regarding use } \\
\text { of the } \\
\text { Internet-based } \\
\text { Services } \\
\text { during the } \\
\text { COVID-19 }\end{array}$} & INT1 & $\begin{array}{l}\text { I intend to use different IBS during the COVID-19 in } \\
\text { the future }\end{array}$ & $\begin{array}{l}\text { Al-Okailay et al. (2020); } \\
\text { Saleem et al. (2020); } \\
\text { Okcu et al. (2019); } \\
\text { Sukendro et al. (2020); } \\
\text { Toe et al. (2019); Nikou } \\
\text { et al. (2017); Rafique et } \\
\text { al. (2020); Briz-Ponce et } \\
\text { al. (2017); Okcu et al. } \\
(2019)\end{array}$ \\
\hline & INT2 & $\begin{array}{l}\text { I plan to use different IBS during the COVID-19 in the } \\
\text { future }\end{array}$ & $\begin{array}{l}\text { Al-Okailay et al. (2020); } \\
\text { Okcu et al. (2019); Toe } \\
\text { et al. (2019); Nikou et al. } \\
\text { (2017); Rafique et al. } \\
(2020) ; \text { Briz-Ponce et al. } \\
(2017) ; \text { Okcu et al. } \\
(2019)\end{array}$ \\
\hline \multirow[b]{2}{*}{$\begin{array}{l}\text { Actual use of } \\
\text { the } \\
\text { Internet-based } \\
\text { Services } \\
\text { during the } \\
\text { COVID-19 }\end{array}$} & AU1 & I use IBS during the COVID-19 & Sukendro et al. (2020) \\
\hline & AU2 & $\begin{array}{l}\text { I use IBS to communicate, interact and work from } \\
\text { home during the COVID-19 }\end{array}$ & Sukendro et al. (2020) \\
\hline
\end{tabular}

\begin{tabular}{llll} 
Facilitating & FC1 & Guidance is available to me & Toe et al. (2019) \\
\cline { 2 - 3 }
\end{tabular}




\begin{tabular}{|c|c|c|c|}
\hline \multirow{4}{*}{$\begin{array}{l}\text { Conditions } \\
\text { (FC) (when I } \\
\text { encounter } \\
\text { difficulties in } \\
\text { using ABS } \\
\text { during the } \\
\text { outbreak of } \\
\text { COVID-19s) }\end{array}$} & FC2 & $\begin{array}{l}\text { Specialized instructions regarding the use of IBS are } \\
\text { available to me }\end{array}$ & Toe et al. (2019) \\
\hline & FC3 & A specific person is available to provide me assistance & $\begin{array}{l}\text { Toe et al. (2019); Nikou } \\
\text { et al. (2017); Briz-Ponce } \\
\text { et al. (2017); Sukendro et } \\
\text { al. (2020) }\end{array}$ \\
\hline & FC4 & I know where to seek assistance & Toe et al. (2019) \\
\hline & FC5 & I am given timely assistance & Toe et al. (2019) \\
\hline \multirow[t]{4}{*}{$\begin{array}{l}\text { Social Impact } \\
\text { (SI) }\end{array}$} & SI1 & $\begin{array}{l}\text { People who influence my behavior to me think that I } \\
\text { should use IBS during the COVID-19 }\end{array}$ & $\begin{array}{l}\text { Nikou et al. (2017); } \\
\text { Briz-Ponce et al. (2017) }\end{array}$ \\
\hline & SI2 & $\begin{array}{l}\text { People who are important to me think that I should use } \\
\text { IBS during the COVID-19 }\end{array}$ & $\begin{array}{l}\text { Nikou et al. (2017); } \\
\text { Briz-Ponce et al. (2017) }\end{array}$ \\
\hline & SI3 & $\begin{array}{l}\text { My friend has been helpful in the use of IBS during the } \\
\text { COVID-19 }\end{array}$ & $\begin{array}{l}\text { Nikou et al. (2017); } \\
\text { Briz-Ponce et al. (2017) }\end{array}$ \\
\hline & SI4 & $\begin{array}{l}\text { In general, my friends and family has supported the use } \\
\text { of IBS during the COVID-19 }\end{array}$ & $\begin{array}{l}\text { Nikou et al. (2017); } \\
\text { Briz-Ponce et al. (2017) } \\
\end{array}$ \\
\hline \multirow{4}{*}{$\begin{array}{l}\text { Task } \\
\text { Technology } \\
\text { FIT (TTF) }\end{array}$} & TTF1 & IBS during the COVID-19 is fit for my requirements & Wu \& Chen (2016) \\
\hline & TTF2 & $\begin{array}{l}\text { Using IBS during the COVID-19 fits with my } \\
\text { education and practice }\end{array}$ & Wu \& Chen (2016) \\
\hline & TTF3 & $\begin{array}{l}\text { It is easy to understand which tools to use for IBS } \\
\text { during the COVID-19 }\end{array}$ & Wu \& Chen (2016) \\
\hline & TTF4 & $\begin{array}{l}\text { Using IBS during the COVID-19 is suitable for helping } \\
\text { me complete my tasks }\end{array}$ & Wu \& Chen (2016) \\
\hline
\end{tabular}

Author contribution Nasir Ishfaq: conceptualization (equal); data curation (lead); formal analysis (lead); investigation (lead); methodology (equal); software (lead); validation (equal); visualization (lead); writingoriginal draft (lead); writing-review and editing (equal). Amir Ishfaq: conceptualization (equal); data curation (lead); formal analysis (lead); investigation (lead); methodology (equal); software (lead); validation (equal); visualization (lead); writing-original draft (lead); writing-review and editing (equal). Saddam Rahim: formal analysis (lead); investigation (lead). Wu Yuanyuan: conceptualization (lead); data curation (supporting); formal analysis (equal); investigation (lead); methodology (lead); project administration (lead); resources (lead). Huan Mengxing: conceptualization (lead); data curation (supporting); formal analysis (equal); investigation (lead); methodology (lead); project administration (lead); resources (lead).

Funding This work was supported by the National Key Research and Development Program of China (grant \#: 2018YFB1404400), and the Hainan Provincial Natural Science Foundation of China (grant \#: 2019CXTD400).

Data availability All of the data used in this paper are included as Supplementary Data.

\section{Declarations}

Ethics approval N/A

Consent to participate N/A

Consent for publication All authors agreed for publication.

Competing interests The authors declare no competing interests.

\section{References}

Ali A, Ahmed M, Hassan N (2020) Socioeconomic impact of COVID-19 pandemic: evidence from rural mountain community in Pakistan. $\mathrm{J}$ Public Affairs:e2355

Allam Z (2020) The forceful reevaluation of cash-based transactions by COVID-19 and its opportunities to transition to cashless systems in digital urban networks. Surveying the Covid-19 Pandemic and its Implications, 107

Al-Okaily M, Alqudah HM, Matar A, Lutfi A, Taamneh A (2020) Impact of COVID-19 pandemic on acceptance of E-learning system in Jordan: a case of transforming. Humanities \& Social Reviews, Vol. 8(4):840-851

Bahadur S, Long W, Shuaib M (2020) Human coronaviruses with emphasis on the COVID-19 outbreak. Virusdisease 31:80-84

Beck L, Ajzen I (1991) Predicting dishonest actions using the theory of planned behavior. J Res Pers 25(3):285-301

Bhatti UA, Huang M, Wu D et al (2019) Recommendation system using feature extraction and pattern recognition in clinical care systems. Enterp Inf Syst 13(3):329-351

Bhatti A, Akram H, Basit HM et al (2020) E-commerce trends during COVID-19 pandemic. International Journal of Future Generation Communication and Networking 13(2):1449-1452

Briz-Ponce L, Pereira A, Carvalho L, Juanes-Méndez JA, García-Peñalvo FJ (2017) Learning with mobile technologies-students' behavior. Comput Hum Behav 72:612-620

Chaudhary H (2020) Analyzing the paradigm shift of consumer behavior towards E-commerce during pandemic lock-down. Available at SSRN 3664668

Chen K, Chen JV, Yen DC (2011) Dimensions of self-efficacy in the study of smartphone acceptance. Comput Stand Interfaces 33(4): $422-431$ 
Coibion O, Gorodnichenko Y, Weber M (2020) Labor markets during the COVID-19 crisis: a preliminary view (No. w27017). National Bureau of Economic Research

Cordente-Rodriguez M, Splendiani S, Silvestrelli P (2020) Measuring propensity of online purchase by using the tam model: evidence from Italian university students. Appl Comput Sci 16(2)

Davis FD (1989) Perceived usefulness, perceived ease of use, and user acceptance of information technology. MIS quarterly:319-340

Dutta A, Fischer HW (2021) The local governance of COVID-19: disease prevention and social security in rural India. World Dev 138:10523

Eger L, Komárková L, Egerová D et al (2021) The effect of COVID-19 on consumer shopping behaviour: generational cohort perspective. J Retail Consum Serv 61:102542

Fana M, Milasi S, Napierala J, Fernandez-Macias E, Vázquez IG (2020) Telework, work organisation and job quality during the COVID-19 crisis: a qualitative study (No. 2020/11). JRC Working Papers Series on Labour, Education and Technology

Farooq M, Raju V (2019) Impact of over-the-top (OTT) services on the telecom companies in the era of transformative marketing. Glob J Flex Syst Manag 20(2):177-188

Hasan SM, Rehman A, Zhang W (2021) Who can work and study from home in Pakistan: evidence from a 2018-19 nationwide household survey. World Dev 138:105197

Hur W-M, Moon TW, Han S-J (2015) The effect of customer incivility on service employees' customer orientation through double-mediation of surface acting and emotional exhaustion. J Serv Theory Pract 25(4):394-413. https://doi.org/10.1108/jstp-02-2014-0034

Ikram M, Zhang Q, Sroufe R, Ferasso M (2020) The social dimensions of corporate sustainability: an integrative framework including COVID-19 insights. Sustainability. 12(20):8747. https://doi.org/10. $3390 /$ su12208747

Javed A (2020) The scope of information and communication technology enabled services in Promoting Pakistan Economy. Asian J Econ Finance Manag:1-9

Kamal MM (2020) The triple-edged sword of COVID-19: understanding the use of digital technologies and the impact of productive, disruptive, and destructive nature of the pandemic. Inform Syst Manag 37(4):310-317

Kong F, Li X, Xia Y, Wang M, Sun X (2020) Technology acceptance model of mobile social media among Chinese college students. J Technol Behav Sci:1-5

Li S, Kallas Z, Rahmani D (2021) Did the COVID-19 lock-down affect consumers' sustainable behaviour in food purchasing and consumption in China? Food Control:108352

Nikou SA, Economides AA (2017) Mobile-based assessment: investigating the factors that influence behavioral intention to use. Comput Educ 109:56-73

Okcu S, Koksalmis GH, Basak E, Calisir F (2019) Factors affecting intention to use big data tools: an extended technology acceptance model. In: Industrial Engineering in the Big Data Era, pp 401-416. Springer, Cham

Paital B, Das K, Parida SK (2020) Inter nation social lock-down versus medical care against COVID-19, a mild environmental insight with special reference to India. Sci Total Environ 138914

Pandey N, Pal A (2020) Impact of digital surge during Covid-19 pandemic: a viewpoint on research and practice. Int J Inf Manag 55: 102171

Rafique H, Shamim A, Anwar F (2019) Investigating acceptance of mobile library application with extended technology acceptance model (TAM). Comput Educ
Roy D, Tripathy S, Kar SK, Sharma N, Verma SK, Kaushal V (2020) Study of knowledge, attitude, anxiety \& perceived mental healthcare need in Indian population during COVID-19. Asian J Psychiatry 51: 102083

Rubab S, Bahadur S, Shuaib M, Rauf A, Zeb A, Shah I et al (2021) Challenging COVID-19 and its outbreak in Pakistan and across the borders. Biosci Res 18(1):284-294

Sagnier C, Loup-Escande E, Lourdeaux D, Thouvenin I, Valléry G (2020) User acceptance of virtual reality: an extended technology acceptance model. Int J Hum-Comput Inter 36(11):993-1007

Saleem MA, Nor KM (2020) The effect of COVID-19 on consumer behavior in Saudi Arabia: switching from brick and mortar stores to E-commerce. Int J Sci Technol Res 9(07):15-28

Sathish R, Manikandan R, Priscila SS, Sara BV, Mahaveerakannan R (2020) A report on the impact of information technology and social media on Covid-19. In 2020 3rd International Conference on Intelligent Sustainable Systems (ICISS), pp 224-230

Shuaib M, Shah AA, Tariq M, Hussain F, Azam N, Rauf A et al (2020) Pakistani perspective, preparation and response to COVID-19: a review. Biosci Res 17(4):3029-3039

Singh S, Srivastava P (2019) Social media for outbound leisure travel: a framework based on technology acceptance model (TAM). J Tour Futur 5(1):43-61

Singh S, Sharma P, Balhara YPS (2021) The impact of nationwide alcohol ban during the COVID-19 lock-down on alcohol use-related internet searches and behaviour in India: an infodemiology study. Drug Alcohol Rev 40(2): 196-200

Soni VD (2020) Global Impact of E-learning during COVID 19. Available at SSRN 3630073

Sukendro S, Habibi A, Khaeruddin K, Indrayana B, Syahruddin S, Makadada FA, Hakim H (2020) Using an extended technology acceptance model to understand students' use of e-learning during Covid-19: Indonesian sport science education context. Heliyon 6(11)

Tang T, Abuhmaid AM, Olaimat M, Oudat DM, Aldhaeebi M, Bamanger E (2020) Efficiency of flipped classroom with online-based teaching under COVID-19. Interact Learn Environ:1-12

Teo T, Doleck T, Bazelais P, Lemay DJ (2019) Exploring the drivers of technology acceptance: a study of Nepali school students. Educ Technol Res Dev 67(2):495-517

Wismantoro Y, Himawan H, Widiyatmoko K (2020) Measuring the interest of smartphone usage by using technology acceptance model approach. J Asian Finance Econ Bus 7(9):613-620

Wu B, Chen X (2017) Continuance intention to use MOOCs: integrating the technology acceptance model (TAM) and task technology fit (TTF) model. Comput Hum Behav 67:221-232

You JJ, Jong D, Wiangin U (2020) Consumers' purchase intention of organic food via social media: the perspectives of task-technology fit and post-acceptance model. Front Psychol 11

Youssef A, Jaafari M, Belhcen L (2020) Factors affecting the online purchase intention during COVID-19 crisis: the case of Morocco. Available at SSRN 3734389

Zhu F, Zhang X (2010) Impact of online consumer reviews on sales: the moderating role of product and consumer characteristics. J Market 74(2):133-148

Publisher's note Springer Nature remains neutral with regard to jurisdictional claims in published maps and institutional affiliations. 